\title{
Phase II study of weekly irinotecan and capecitabine treatment in metastatic colorectal cancer patients
}

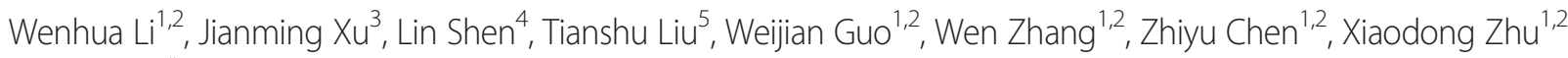
and $\operatorname{Jin} \mathrm{Li}^{1,2^{*}}$

\begin{abstract}
Background: The purpose of this phase II study was to evaluate the safety and efficacy of weekly irinotecan and capecitabine (wXELIRI) treatment in patients with metastatic colorectal cancer, specifically the rate of severe diarrhea.

Methods: Patients with unresectable histologically confirmed metastatic colorectal cancer with measurable disease received weekly irinotecan $90 \mathrm{mg} / \mathrm{m}^{2}$ on day 1 and capecitabine $1200 \mathrm{mg} / \mathrm{m}^{2}$ twice daily on days $1-5$. Patients naïve to systemic chemotherapy for metastatic disease or who had failed FOLFOX (infusional 5-fluorouracil [5-FU], leucovorin, and oxaliplatin) or XELOX (capecitabine plus oxaliplatin) as first-line treatment were eligible. The primary endpoint was the rate of grade 3/4 diarrhea. Secondary endpoints included progression-free survival (PFS), overall survival (OS), and safety.

Results: A total of 52 patients were enrolled, 30 of whom received WXELIRI as first-line treatment and 22 as second-line treatment. Grade 4 diarrhea was observed in one patient and the rate of grade 3/4 diarrhea was $7.7 \%$. The other common grade $3 / 4$ toxicities included leukopenia (9.6\%), neutropenia (17.3\%), nausea (3.8\%), vomiting (3.8\%), fatigue (1.9\%), and hand-foot syndrome (1.9\%). The median progression-free survival and overall survival for the 30 patients treated in the first-line setting was 8.5 and 16.3 months, while those for the 22 patients treated in the second-line setting was 5.0 and 10.7 months, respectively.

Conclusions: The wXELIRI regimen resulted in a low rate of severe diarrhea with an acceptable toxicity profile. This study provides a basis for a subsequent randomized controlled study of WXELIRI versus FOLFIRI (irinotecan, 5-FU, and folinic acid) to further explore the efficacy and safety of this regimen.
\end{abstract}

Trial registration: ClinicalTrials.gov: NCT01322152.

Keywords: Colorectal neoplasms, Irinotecan, Capecitabine, Antineoplastic agents

\section{Background}

Colorectal cancer, the second leading cause of cancer death in the USA, has increased in frequency in China in recent years. Based on a registry in Shanghai, a city with a population of 23 million, colorectal cancer has become the third most prevalent malignancy [1]. Approximately

\footnotetext{
* Correspondence: fudanlijin@163.com

'Department of Medical Oncology, Fudan University Shanghai Cancer Center, 270 Dong-An Road, Shanghai 200032, China

${ }^{2}$ Department of Oncology, Shanghai Medical College, Fudan University,

Shanghai, China

Full list of author information is available at the end of the article
}

$50-60 \%$ of patients diagnosed with colorectal cancer will develop metastases [2,3], for whom systematic chemotherapy is the standard treatment.

Irinotecan combined with continuous infusion of 5fluorouracil (5-FU) and folinic acid (the FOLFIRI regimen) is the established option for first- and/or second-line treatment of metastatic colorectal cancer. Capecitabine, an oral fluoropyrimidine that mimics continuous 5-FU infusion by generating 5 -FU preferentially in the tumor tissues [4], has been shown to have comparable efficacy to 5 -FU/folinic acid as first-line treatment of metastatic colorectal cancer, with an additional benefit of convenient 
administration without hospitalization [5]. The combination of irinotecan and capecitabine (XELIRI) has been assessed, but the associated gastrointestinal toxicity, especially the incidence of severe diarrhea, affected the feasibility of this regimen $[6,7]$. The incidence of grade $3 / 4$ diarrhea was higher (17-36\% vs $12-15 \%)$ with a 3 -week XELIRI regimen than with the FOLFIRI regimen [8-11], and non-superior time to progression (TTP; 6-9 months vs 6.7-8.5 months) and overall survival (OS; 13-20 months vs 14.8-17.4 months) were observed [12-14]. Toxicityinduced dose reduction and treatment delay weakened the efficacy of the XELIRI regimen.

To reduce the side effect of diarrhea, a 2-week XELIRI regimen was tried recently. The 2 -week regimen (irinotecan on day 1 , capecitabine on days $2-8$ or days $1-5$ and 8-12) exhibited promising activity (TTP, 8-10 months, OS, 15-19 months) with improved tolerability (grade 3/4 diarrhea, $8.1-15.0 \%)[15,16]$, but an increased rate of severe diarrhea was noted in elderly patients, which resulted in dose reduction [15].

This study aimed to evaluate the tolerability of a weekly XELIRI regimen as first- or second-line treatment in patients with metastatic colorectal cancer. The dose and schedule was chosen based on the assumption that 5 days on/2 days off administration of capecitabine may better mimic continuous 5-FU infusion [16]. The dose of irinotecan was calculated as a weekly dose according to the FOLFIRI regimen [14]. The study investigated the possibility of a further reduction of the rate of severe diarrhea with weekly XELIRI treatment, and evaluated the safety and efficacy of this schedule in Chinese patients with metastatic colorectal cancer.

\section{Methods}

\section{Patients}

Patients aged 18-70 years with histologically or cytologically confirmed advanced colorectal adenocarcinoma, with an Eastern Cooperative Oncology Group performance status of 0 to 1 and life expectancy of $\geq 3$ months were eligible. Patients who were chemotherapy-naive or who had failed first-line treatment with either XELOX or FOLFOX were enrolled if they had at least one measurable disease lesion according to the Response Evaluation Criteria in Solid Tumors (RECIST) criteria, version 1.1. Previous (neo) adjuvant chemotherapy was permitted if it had been completed $\geq 6$ months before enrollment, although prior irinotecan therapy was not allowed. Patients were required to have adequate bone marrow, hepatic, and renal function. Patients with previous chronic inflammatory bowel disease, chronic diarrhea or recurrent bowel obstruction, pelvic radiotherapy within 6 months, or symptomatic brain metastases were excluded. The study was approved by the independent ethics committee of Fudan University Shanghai Cancer
Center, Shanghai, China and registered at ClinicalTrials. gov (NCT01322152). The study was carried out in accordance with the Declaration of Helsinki. All patients provided written informed consent before study entry.

\section{Treatment}

All enrolled patients received a weekly regimen of irinotecan and capecitabine (wXELIRI), as follows: irinotecan (Campto ${ }^{\oplus}$, Pfizer) $90 \mathrm{mg} / \mathrm{m}^{2}$ given intravenously on day 1 ; capecitabine (Xeloda ${ }^{\oplus}$, Roche) $1200 \mathrm{mg} / \mathrm{m}^{2}$ given orally twice daily on days 1-5. The treatment cycles were administered every week until disease progression or unacceptable toxicity, or consent withdrawal. For patients with poor tolerance to toxicities, treatment delay was permitted for no more than 2 weeks.

Unless contraindicated, atropine could be given to prevent the cholinergic adverse effects (including early diarrhea). Loperamide was recommended as the standard anti-diarrhea treatment, and other symptomatic treatment could be given according to the institution's practice guidelines.

\section{Dose modification}

Dose adjustments were made based on the worst grade of toxicity encountered during the previous cycle. For hematological toxicities, the dose of chemotherapeutic drugs was reduced in the following cases: grade 4 neutropenia or leukopenia; grade 3 or greater febrile neutropenia; grade 3 or greater thrombocytopenia. For nonhematological toxicity, the dose of related drug was reduced when grade 3 or greater toxicities occurred (except for alopecia). The dose of irinotecan or capecitabine was reduced by $25 \%$ of the starting dose. If a patient required more than two successive dose reductions, therapy was dicontinued.

Treatment was delayed until the absolute neutrophil count was $\geq 1.5 \times 10^{9} / \mathrm{L}$ and platelet count was $\geq 80 \times$ $10^{9} / \mathrm{L}$, and recovery to grade $\leq 1$ for mucositis, diarrhea and other toxicities (with exception of alopecia).The maximum authorized delay is of 2 weeks.

\section{Assessments}

Pretreatment assessment included a detailed medical history, physical examination, routine laboratory tests, and performance status. Laboratory evaluation included a routine blood count, urinalysis, and electrolyte, renal, and liver function tests. Adverse events and concomitant medications were recorded at the end of each cycle. Toxicity was evaluated and graded according to the National Cancer Institute Common Terminology Criteria for Adverse Events, version 4.0.

Radiographic scans (computed tomography or magnetic resonance imaging) for efficacy evaluation were conducted at baseline and every 2 months thereafter according to the 
RECIST 1.1 guidelines. The best overall response was reported. Survival status was assessed every 3 months after discontinuation of study treatment.

\section{Statistical analysis}

This phase II study was designed to assess the rate of severe diarrhea (calculated as the percentage of patients with grade 3 and grade 4 diarrhea) with the wXELIRI regimen. The rate of severe diarrhea with the 2-week XELIRI or the FOLFIRI regimens was reported as 15\% $[15,17]$, and we supposed that the rate with the wXELIRI regimen was, at most, 5\%. A one-stage Fleming design, with an exact significance level of $\mathrm{p}=0.05$ and a power of $80 \%$, was used to test the hypothesis. With a sample size of 52 evaluable patients, the regimen would be declared promising if less than 6 patients with severe diarrhea were observed.

The efficacy analysis included all patients who received at least one dose of study medication and had at least one efficacy evaluation after baseline. For the safety analysis, all patients who received one dose of study medication were included. The primary study end point was the rate of severe diarrhea. Secondary end points were PFS (defined as the time between the first dose of study medication and first documented disease progression or death), ORR, DCR (defined as the percentage of patients with CR, PR, and SD for at least 8 weeks), OS (defined as the time between the first dose of study medication and death), and safety.

Survival function of time-to-event end points was estimated by using the Kaplan-Meier method. Chi-square test was performed for enumeration data on response rate and clinical benefit rate.

\section{Results}

\section{Patients}

From March 2011 to October 2012, a total of 52 patients ( 25 men and 27 women), aged from 26 to 70 years (median, 60 years) with advanced colorectal cancer received wXELIRI treatment. Previous chemotherapy regimens for the patients receiving second-line treatment included FOLFOX (infusional 5-FU, leucovorin, and oxaliplatin) and XELOX (capecitabine plus oxaliplatin). Table 1 shows the patients' demographic and clinical characteristics at enrollment.

\section{Treatment}

Up to 31 April 2013, the 52 enrolled patients had received a total of 644 cycles of wXELIRI. The median number of treatment cycles was 12 (range, 1-50). Median dose

Table 1 Clinical and demographic characteristics at enrollment $(\mathbf{N}=52)$

\begin{tabular}{|c|c|c|c|}
\hline Characteristic & $\begin{array}{l}\text { All patients } \\
\text { Number (\%) }\end{array}$ & $\begin{array}{l}\text { First-line treatment } \\
\text { Number (\%) }\end{array}$ & $\begin{array}{l}\text { Second-line treatment } \\
\text { Number (\%) }\end{array}$ \\
\hline & & $30(57.7)$ & $22(42.3)$ \\
\hline Median age (range), years & $60(32-70)$ & $60(32-70)$ & $60(26-68)$ \\
\hline \multicolumn{4}{|l|}{ ECOG score } \\
\hline 0 & $20(38.5)$ & $10(33.3)$ & $10(45.5)$ \\
\hline 1 & $32(61.5)$ & $20(67.7)$ & $12(54.5)$ \\
\hline \multicolumn{4}{|l|}{ Sex } \\
\hline Male & $32(61.5)$ & $18(60.0)$ & $14(63.6)$ \\
\hline Female & $20(38.5)$ & $12(40.0)$ & $8(36.4)$ \\
\hline \multicolumn{4}{|l|}{ Primary lesion site } \\
\hline Colon & $32(61.5)$ & $16(53.3)$ & $16(72.7)$ \\
\hline Rectum & $20(38.5)$ & $14(46.7)$ & $6(27.3)$ \\
\hline Positive history of diabetes & $9(17.3)$ & $5(16.7)$ & $4(18.2)$ \\
\hline Primary tumor resection & $46(88.5)$ & $26(86.7)$ & $20(90.9)$ \\
\hline \multicolumn{4}{|l|}{ Site of metastasis } \\
\hline Liver & $31(59.6)$ & $16(53.3)$ & $15(68.2)$ \\
\hline Lung & $18(34.6)$ & $13(43.3)$ & $5(22.7)$ \\
\hline Abdominal cavity & $18(34.6)$ & $8(26.7)$ & $10(45.5)$ \\
\hline \multicolumn{4}{|l|}{ Number of metastatic lesions } \\
\hline Single & $24(46.2)$ & $15(50.0)$ & $9(40.9)$ \\
\hline Multiple & $28(53.8)$ & $15(50.0)$ & $13(59.1)$ \\
\hline
\end{tabular}

ECOG: Eastern Cooperative Oncology Group. 
intensities (i.e. the actual dose administered divided by the planned dose) were $80.0 \%$ for irinotecan, and $78.9 \%$ for capecitabine. Thirty treatment cycles $(4.7 \%)$ were delayed for 23 patients - 22 cycles for 15 patients receiving wXELIRI as first-line treatment and 8 cycles for 8 patients receiving wXELIRI as second-line treatment. The drug dose was reduced in 80 cycles $(12.4 \%)$ in 7 patients -28 cycles for 4 patients receiving wXELIRI as first-line treatment and 52 cycles for 3 patients receiving wXELIRI as second-line treatment. Leucopenia, diarrhea, nausea, vomiting, and hand-foot syndrome were the main causes of dose delay and reduction.

\section{Safety}

The overall incidence of grade $3 / 4$ adverse events was $55.5 \%$. The most common adverse events $(\geq 20 \%)$ were neutropenia, leucopenia, diarrhea, nausea, vomiting, anorexia, and fatigue (Table 2). The rate of severe diarrhea, the primary study end point, was $7.7 \%$ (6.7\% and $9.0 \%$ for the first- and second-line settings, respectively), with one case of grade 4 diarrhea in the second-line setting (Table 3). Grade 3 diarrhea occurred in three patients, one each during the first, third, and fifth treatment cycles, and was relieved by symptomatic treatment for diarrhea and dehydration. Subsequent re-treatment did not result in diarrhea greater than grade 2 . The incidence of grade $1 / 2$ diarrhea was $40.4 \%$, and the symptoms were relieved after standard use of loperamide and symptomatic supportive treatment in most patients.

Nausea and vomiting was another frequent gastrointestinal reaction, with an incidence of $38.5-42.3 \%$. After prophylactic administration of an antiemetic drug (5-hydroxytryptamin 3 [5-HT 3] receptor antagonists), nausea and vomiting was tolerable in most cases. One patient had dose reduction and delayed treatment due to intolerable grade 3 vomiting.

The major hematological toxicities were leucopenia and neutropenia. Three patients developed grade 4

Table 2 Incidence of adverse reactions caused by weekly irinotecan and capecitabine $(\mathbf{N}=\mathbf{5 2}$ )

\begin{tabular}{|c|c|c|c|c|}
\hline \multirow[t]{2}{*}{ Adverse reaction } & Grade I & Grade II & Grade III & Grade IV \\
\hline & Number (\%) & Number (\%) & Number (\%) & Number (\%) \\
\hline \multicolumn{5}{|l|}{ Hematologic toxicity } \\
\hline Leukopenia & $12(23.1)$ & $14(26.9)$ & $5(9.6)$ & $0(0)$ \\
\hline Neutropenia & $9(17.3)$ & $10(19.2)$ & $6(11.5)$ & $3(5.8)$ \\
\hline Febrile neutropenia & $3(5.8)$ & $0(0)$ & $1(1.9)$ & $0(0)$ \\
\hline Thrombocytopenia & $5(9.6)$ & $3(5.8)$ & $0(0)$ & $0(0)$ \\
\hline Anemia & $7(13.5)$ & $13(25)$ & $1(1.9)$ & $0(0)$ \\
\hline \multicolumn{5}{|l|}{ Non-hematologic toxicity } \\
\hline Diarrhea & $16(30.8)$ & $5(9.6)$ & $3(5.8)$ & $1(1.9)$ \\
\hline Nausea & $13(25.0)$ & $7(13.5)$ & $2(3.8)$ & $0(0)$ \\
\hline Vomiting & $7(13.5)$ & $11(21.2)$ & $2(3.8)$ & $0(0)$ \\
\hline Anorexia & $11(21.2)$ & $3(5.8)$ & $0(0)$ & $0(0)$ \\
\hline Fatigue & $11(21.2)$ & $8(15.4)$ & $1(1.9)$ & $0(0)$ \\
\hline Alopecia & $5(9.6)$ & $0(0)$ & $0(0)$ & $0(0)$ \\
\hline Hand-foot syndrome & $3(5.8)$ & $0(0)$ & $1(1.9)$ & $0(0)$ \\
\hline Oral ulceration & $5(9.6)$ & $1(0)$ & $1(1.9)$ & $0(0)$ \\
\hline Venous thrombus & $1(1.9)$ & $0(0)$ & $0(0)$ & $0(0)$ \\
\hline Pulmonary infection & $1(1.9)$ & $1(1.9)$ & $0(0)$ & $0(0)$ \\
\hline Hyperbilirubinemia & $2(3.8)$ & $0(0)$ & $0(0)$ & $0(0)$ \\
\hline Constipation & $1(1.9)$ & $1(1.9)$ & $0(0)$ & $0(0)$ \\
\hline Elevated creatinine & $1(1.9)$ & $0(0)$ & $0(0)$ & $0(0)$ \\
\hline Elevated blood glucose & $1(1.9)$ & $1(1.9)$ & $0(0)$ & $0(0)$ \\
\hline Respiratory alkalosis & $1(1.9)$ & $0(0)$ & $0(0)$ & $0(0)$ \\
\hline Pain & $3(5.8)$ & $0(0)$ & $0(0)$ & $0(0)$ \\
\hline Hypophosphatemia & $0(0)$ & $0(0)$ & $1(1.9)$ & $0(0)$ \\
\hline Hypomagnesemia & $0(0)$ & $1(1.9)$ & $0(0)$ & $0(0)$ \\
\hline Hypokalemia & $0(0)$ & $0(0)$ & $1(1.9)$ & $0(0)$ \\
\hline
\end{tabular}


Table 3 Incidence of diarrhea after first- and second-line weekly irinotecan and capecitabine

\begin{tabular}{llllll}
\hline & Total & $\begin{array}{l}\text { Grade I } \\
\text { Number (\%) }\end{array}$ & $\begin{array}{l}\text { Grade II } \\
\text { Number (\%) }\end{array}$ & $\begin{array}{l}\text { Grade III } \\
\text { Number (\%) }\end{array}$ & $\begin{array}{l}\text { Grade IV } \\
\text { Number (\%) }\end{array}$ \\
\hline First-line treatment & $30(57.7)$ & $10(33.3)$ & $3(10)$ & $2(6.7)$ & $0(0)$ \\
Second-line treatment & $22(42.3)$ & $6(27.3)$ & $2(9.1)$ & $1(4.5)$ & $1(4.5)$ \\
\hline
\end{tabular}

neutropenia and one developed grade 3 febrile neutropenia. After symptomatic therapy and prophylactic antibiotic treatment, all patients recovered. The incidence of mild to moderate anemia was $38.5 \%$. One patient discontinued treatment because of grade 3 anemia complicated by grade 3 fatigue after 5 cycles of wXELIRI, and one patient had the capecitabine dose reduced due to the grade 3 hand-foot syndrome after 16 cycles. Table 4 shows the adverse reactions.

\section{Efficacy}

After a median follow-up of 13.9 months (range, 1-24 months), 25 of 30 patients (83.3\%) treated with wXELIRI in the first-line setting experienced disease progression, and 16 patients $(53.3 \%)$ died (Table 4$)$. The median OS was 16.3 months (95\% confidence interval [CI]: 10.4722.13 months) and the median progression-free survival (PFS) was 8.5 months (95\% CI: 6.22-10.78 months) (Figure 1). Ten patients experienced partial response (PR) and 11 patients had stable disease (SD), whereas no complete response (CR) was observed and 3 patients did not have response evaluation due to withdrawal of consent after two cycles. The objective response rate (ORR) was $37 \%$ (10/27 patients) and the disease control rate (DCR) was $77.7 \%$ (21/27 patients). Secondary R0 metastasectomy was performed in 2 patients after 6 cycles.

In patients pretreated with FOLFOX or XELOX $(n=22)$, the median PFS was 5.0 months (95\% CI: 1.74-8.26 months) and the median OS was 10.7 months (95\% CI: 5.8015.60 months), with a median follow-up period of 13.8 months (range, 1-17 months) (Figure 2). Among the 21 evaluable patients in the second-line setting, three (14.3\%) achieved PR, and 13 (61.9\%) had stable disease, whereas five $(23.8 \%)$ had disease progression at the first efficacy evaluation. One patient withdrew from the study due to personal reasons after one cycle.

\section{Discussion}

This study demonstrated that patients with colorectal cancer experienced a relatively low incidence of severe diarrhea with the wXELIRI regimen as first- or secondline treatment. The incidence of grade 3 and grade 4 diarrhea was $5.8 \%$ and $1.9 \%$, respectively. Among the 30 patients who received the study treatment in the firstline setting, the rate of grade 3 diarrhea was only $6.7 \%$ and no grade 4 diarrhea was observed. This was much lower than that observed with the 3 -week or 2-week XELIRI [8,10,11,15] and FOLFIRI [12,13] regimens. In

Table 4 Analysis of efficacy of weekly irinotecan and capecitabine as first- or second line treatment

\begin{tabular}{|c|c|c|c|c|}
\hline \multirow[t]{2}{*}{ Variable } & \multicolumn{2}{|c|}{ First-line treatment $(n=30)$} & \multicolumn{2}{|c|}{ Second-line treatment $(n=22)$} \\
\hline & Number (\%) & $95 \% \mathrm{Cl}$ & Number (\%) & $95 \% \mathrm{Cl}$ \\
\hline \multicolumn{5}{|l|}{ Overall survival } \\
\hline Deaths & $16(53.3)$ & & $12(54.5)$ & \\
\hline Median OS (months) & 16.3 & $10.47-22.13$ & 10.7 & $5.80-15.60$ \\
\hline \multicolumn{5}{|l|}{ Progression-free survival } \\
\hline Progression events & $25(83.3)$ & & $20(90.9)$ & \\
\hline Median PFS (months) & 8.5 & $6.22-10.78$ & 5.0 & $1.74-8.26$ \\
\hline Response & 27 & & 21 & \\
\hline ORR & $10(37.0)$ & & $3(14.3)$ & \\
\hline PR & $10(37.0)$ & & $3(14.3)$ & \\
\hline SD & $11(40.7)$ & & $13(61.9)$ & \\
\hline PD & $6(22.2)$ & & $5(23.8)$ & \\
\hline \multicolumn{5}{|l|}{ Treatment cycles } \\
\hline Total & 378 & & 266 & \\
\hline Median number of cycles (range) & $12(1-50)$ & & $12(1-33)$ & \\
\hline Median treatment period (months) & 3.7 & & 3.7 & \\
\hline
\end{tabular}

CR: complete response; ORR: overall response rate; OS: overall survival; PD: progressive disease; PFS: progression-free survival; PR: partial response; SD: stable disease. 

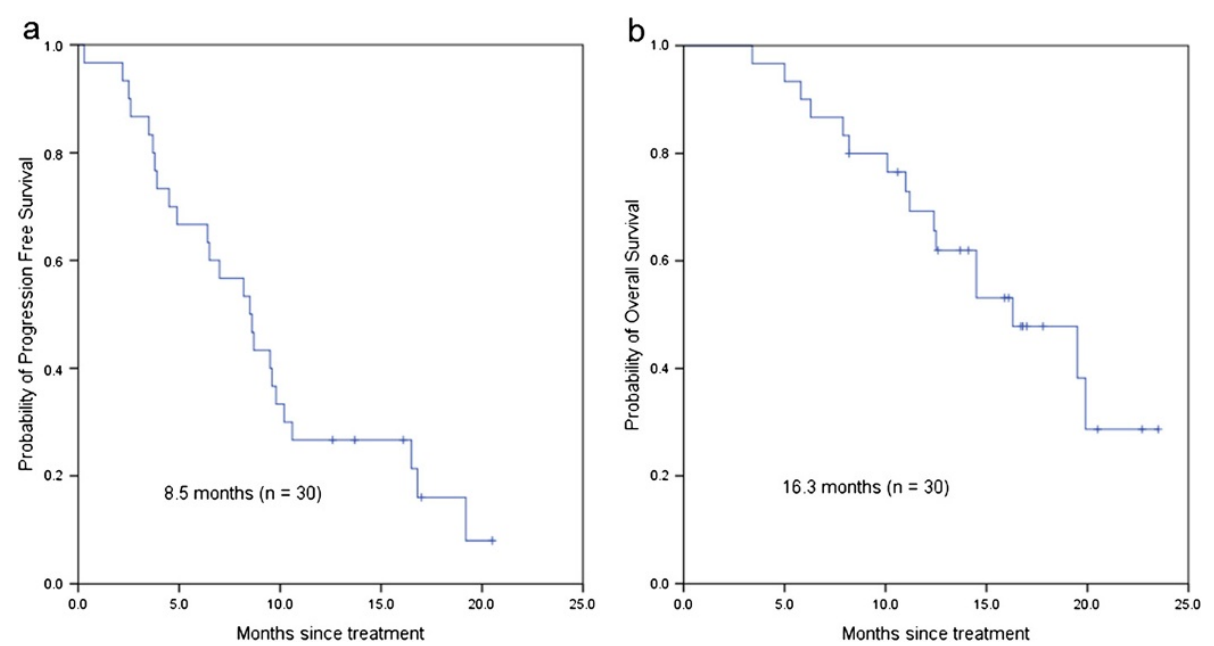

Figure 1 Overall survival and progression-free survival in the first-line setting. (a) progression-free survival; (b) overall survival.

the MAC-6 study [16], the 5 days on/2 days off administration of capecitabine was introduced to ensure the absence of a completely drug-free interval during treatment, while maintaining a reasonable dose intensity, and a rate of grade 3 diarrhea of $8.1 \%$ was obtained. We have also demonstrated a similar low incidence of severe diarrhea in this series when using the same dosing schedule of capecitabine and dividing the dose of irinotecan from the FOLFIRI regimen into once weekly administration. In the literature, the median time for delayed diarrhea caused by irinotecan was 6-14 days after administration $[18,19]$. Diarrhea may be aggravated in the second week when using the traditional regimen of capecitabine from days 1 to 14 every 21 days, which may result in discontinuation of the oral fluoropyrimidine causing under-dosage. Our results indicate that weekly use of capecitabine is feasible and tolerable with less drug interruption when combined with irinotecan.

We analyzed the efficacy and survival data according to the treatment setting. Survival in this study was similar to that in previous studies in patients undergoing first-line treatment with irinotecan and capecitabine (Table 5). About $10 \%$ of the patients in our study accepted targeted therapy as subsequent treatment. The median OS for first-line treatment was comparable with the published data for patients undergoing chemotherapy [20-23]. In the second-line setting, wXELIRI showed promising efficacy. Among 22 patients who had failed prior oxaliplatin, the ORR was $14.3 \%$ and the median PFS was 5.0 months, which were significantly superior to the ORR of $4 \%$ and PFS of 2.5 months with FOLFIRI after failure of FOLFOX in the GERGOR study [17], and the median OS exceeded
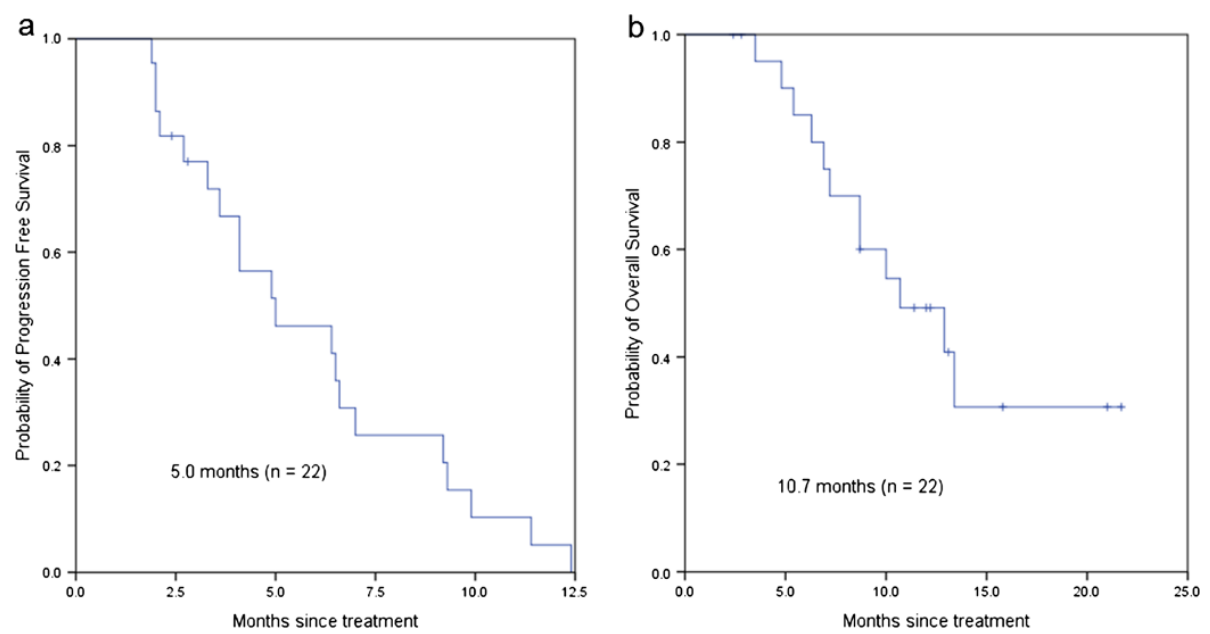

Figure 2 Overall survival and progression-free survival in the second-line setting. (a) progression-free survival; (b) overall survival. 
Table 5 Summary of clinical trials of capecitabine and irinotecan in the first-line setting

\begin{tabular}{|c|c|c|c|c|c|c|c|}
\hline Study & Year & Treatment & $\begin{array}{l}\text { Number of } \\
\text { patients }\end{array}$ & ORR (\%) & $\begin{array}{l}\text { PFS } \\
\text { (months) }\end{array}$ & $\begin{array}{l}\text { OS } \\
\text { (months) }\end{array}$ & $\begin{array}{l}\text { Grade } 3 / 4 \\
\text { diarrhea (\%) }\end{array}$ \\
\hline \multirow[t]{2}{*}{ Bajetta, et al [9] } & 2004 & CAPIRI vs XELIRI & 140 & CAPIRI 44 & CAPIRI 7.6 & - & CAPIRI 17 \\
\hline & & & & XELIRI 47 & XELIRI 8.3 & & XELIRI 36 \\
\hline \multirow[t]{2}{*}{ Borner, et al [8] } & 2005 & CAPIRI vs XELIRI & 75 & CAPIRI 34 & CAPIRI 6.9 & CAPIRI 17.4 & CAPIRI 34 \\
\hline & & & & XELIRI 35 & XELIRI 9.2 & XELIRI 24.7 & XELIRI 19 \\
\hline Cartwright, et al [10] & 2005 & XELIRI & 49 & 45 & 6.2 & 13.4 & 20 \\
\hline Patt, et al [11] & 2007 & XELIRI & 52 & 46 & ТТР 7.1 & 15.6 & 20 \\
\hline Rea, et al [24] & 2005 & XELIRI & 57 & 42 & ТTP 8.3 & - & 9 \\
\hline Garcia-Alfonso, et al [15] & 2009 & XELIRI (every 2 weeks) & 53 & 40 & ТТР 8.4 & 19.3 & 15.9 \\
\hline Choi, et al [16] & 2008 & XELIRI (every 2 weeks) & 43 & 51 & ТTP 10.1 & 15.4 & 8.1 \\
\hline
\end{tabular}

CAPIRI: capecitabine and irinotecan; ORR: objective response rate; OS: overall survival; PFS: progression-free survival; TTP: time to progression; XELIRI: irinotecan and capecitabine.

10 months. Given these data from a limited number of patients, it would be interesting to ascertain the survival data for second-line treatment of colorectal cancer in a greater number of patients.

The low rate of severe diarrhea enabled a greater intensity of chemotherapy to be achieved, thus ensuring improved efficacy; a treatment delay of only $4.7 \%$ was observed in this study. Patients experienced more grade $3 / 4$ neutrophilia than in the MAC-6 study [16], but hematological suppression was easily controlled with granulocyte colony-stimulating factor support.

It should be admitted that the doses of the weekly regimen of irinotecan and capecitabine in our study were not established through a formal phase I study. However, the tolerable dose for weely-used irinotecan was evaluated in the previous phase I trial [25], of which irinotecan with a dose of $100 \mathrm{mg} / \mathrm{m}^{2}$ was given on days 1 and 8 , and capecitabine with $2000 \mathrm{mg} / \mathrm{m}^{2}$ on days 1-14 of a 3-week cycle was recommended. In our study, the dose of irinotecan was chosed based on that in the FOLFIRI regimen with $180 \mathrm{mg} / \mathrm{m}^{2}$ for 2 weeks [17], equal to $90 \mathrm{mg} / \mathrm{m}^{2}$ weekly. Although the planned dose intensities of irinotecan and capecitabine with wXELIRI were higher than those with the biweekly [15] or every three weeks $[10,11]$ irinotecan/capecitabine regimen, the rate of diarrhea decreased while the survival data was similar, suggesting the feasibility of weekly used regimen.

Additional use of targeted therapy based on irinotecan and capecitabine is a new direction [20,26-28]. Recent study data indicated that the 3 -week XELIRI regimen combined with bevacizumab had comparable efficacy to FOLFIRI combined with bevacizumab, with incidences of grade 3/4 diarrhea and agranulocytosis of $19 \%$ and $13 \%$, respectively [20]. The XELIRI plus cetuximab regimen also achieved good efficacy with an OS of more than 20 months [28], but poor tolerance was a concern as $32 \%$ of patients required dose reduction [29]. Whether the wXELIRI regimen could become an alternative to combination therapy with targeted drugs needs further investigation.

\section{Conclusions}

The weekly irinotecan and capecitabine combination is associated with a low incidence of severe diarrhea and has an acceptable toxicity profile. wXELIRI could be an alternative regimen for patients with metastatic colorectal cancer, especially in the second-line setting. Further randomized controlled studies are needed to evaluate the efficacy and safety of this regimen in a larger sample size.

\section{Abbreviations}

CR: Complete response; DCR: Disease control rate; ECOG: Eastern cooperative oncology group; FOLFIRI: Irinotecan, continuous infusion of 5-fluorouracil, and folinic acid; FOLFOX: 5-fluorouracil, leucovorin, and oxaliplatin; 5-FU: 5-fluorouracil; ORR: Overall response rate; OS: Overall survival; PFS: Progression-free survival; PR: Partial response; RECIST: Response evaluation criteria in solid tumors; SD: Stable disease; TTP: Time to progression; XELIRI: Irinotecan and capecitabine; XELOX: Capecitabine and oxaliplatin.

\section{Competing interests}

The authors declare that they have no competing interests.

\section{Authors' contributions}

WL participated in acquisition of data, analysis and interpretation of data, and drafting of the manuscript. JX, LS, TL, WZ, WG, ZC, XZ carried out the study during clinical observation, follow up, collected the clinical data for analysis. $J L$ conceived of the study, participated in its design and coordination and revised the final manuscript. All authors have read and approved the final manuscript.

\section{Authors' information}

J: MD, PhD, Professor, Director of Department of Medical Oncology, Fudan University Shanghai Cancer Center.

\section{Acknowledgements}

The study was supported by CSCO-Tonghui 2011 Fund (No: Y-H2010-013), awarded by Chinese Society of Clinical Oncology. 


\section{Author details}

'Department of Medical Oncology, Fudan University Shanghai Cancer Center, 270 Dong-An Road, Shanghai 200032, China. ${ }^{2}$ Department of Oncology, Shanghai Medical College, Fudan University, Shanghai, China. ${ }^{3}$ Department of Gastrointestinal Oncology, 307 Hospital of PLA, Academy of Military Medical Science, Beijing, China. ${ }^{4}$ Department of Gastrointestinal Oncology, Peking University Cancer Hospital \& Institute, Beijing, China. ${ }^{5}$ Department of Medical Oncology, Zhongshan Hospital, Fudan University, Shanghai, China

Received: 1 January 2014 Accepted: 16 December 2014

Published: 19 December 2014

\section{References}

1. Shanghai municipal center for disease control and prevention: Shanghai Cancer Report 2007. Shanghai J Prev Med 2010, 22(7):399-400.

2. Van Cutsem E, Nordlinger B, Adam R, Kohne CH, Pozzo C, Poston G, Ychou M, Rougier P: Towards a pan-European consensus on the treatment of patients with colorectal liver metastases. Eur J Cancer 2006, 42(14):2212-2221.

3. Yoo PS, Lopez-Soler Rl, Longo WE, Cha CH: Liver resection for metastatic colorectal cancer in the age of neoadjuvant chemotherapy and bevacizumab. Clin Colorectal Cancer 2006, 6(3):202-207.

4. Miwa M, Ura M, Nishida M, Sawada N, Ishikawa T, Mori K, Shimma N, Umeda I, Ishitsuka H: Design of a novel oral fluoropyrimidine carbamate, capecitabine, which generates 5 -fluorouracil selectively in tumours by enzymes concentrated in human liver and cancer tissue. Eur J Cancer 1998, 34(8):1274-1281

5. Van Cutsem E, Findlay M, Osterwalder B, Kocha W, Dalley D, Pazdur R, Cassidy J, Dirix L, Twelves C, Allman D, Seitz JF, Scholmerich J, Burger HU, Verweij J: Capecitabine, an oral fluoropyrimidine carbamate with substantial activity in advanced colorectal cancer: results of a randomized phase II study. J Clin Oncol 2000, 18(6):1337-1345.

6. Fuchs CS, Marshall J, Mitchell E, Wierzbicki R, Ganju V, Jeffery M, Schulz J, Richards D, Soufi-Mahjoubi R, Wang B, Barrueco J: Randomized, controlled trial of irinotecan plus infusional, bolus, or oral fluoropyrimidines in firstline treatment of metastatic colorectal cancer: results from the BICC-C Study. J Clin Oncol 2007, 25(30):4779-4786.

7. Kohne $\mathrm{CH}$, De Greve J, Hartmann JT, Lang I, Vergauwe P, Becker K Braumann D, Joosens E, Muller L, Janssens J, Bokemeyer C, Reimer P, Link H, Spath-Schwalbe E, Wilke HJ, Bleiberg H, Van Den Brande J, Debois M, Bethe U, Van Cutsem E: Irinotecan combined with infusional 5-fluorouracil/ folinic acid or capecitabine plus celecoxib or placebo in the first-line treatment of patients with metastatic colorectal cancer. EORTC study 40015. Ann Oncol 2008, 19(5):920-926.

8. Borner MM, Bernhard J, Dietrich D, Popescu R, Wernli M, Saletti P, Rauch D, Herrmann R, Koeberle D, Honegger H, Brauchli P, Lanz D, Roth AD: A randomized phase II trial of capecitabine and two different schedules of irinotecan in first-line treatment of metastatic colorectal cancer: efficacy, quality-of-life and toxicity. Ann Oncol 2005, 16(2):282-288.

9. Bajetta E, Di Bartolomeo M, Mariani L, Cassata A, Artale S, Frustaci S, Pinotti G, Bonetti A, Carreca I, Biasco G, Bonaglia L, Marini G, lannelli A, Cortinovis D. Ferrario E, Beretta E, Lambiase A, Buzzoni R: Randomized multicenter Phase II trial of two different schedules of irinotecan combined with capecitabine as first-line treatment in metastatic colorectal carcinoma. Cancer 2004, 100(2):279-287.

10. Cartwright T, Lopez T, Vukelja SJ, Encarnacion C, Boehm KA, Asmar L: Results of a phase II open-label study of capecitabine in combination with irinotecan as first-line treatment for metastatic colorectal cancer. Clin Colorectal Cancer 2005, 5(1):50-56.

11. Patt $Y Z$, Lee FC, Liebmann JE, Diamandidis D, Eckhardt SG, Javle M, Justice GR, Keiser W, Salvatore JR, Bexon A, Lin E: Capecitabine plus 3-weekly irinotecan (XELIRI regimen) as first-line chemotherapy for metastatic colorectal cancer: phase II trial results. Am J Clin Oncol 2007, 30(4):350-357.

12. Saltz LB, Cox JV, Blanke C, Rosen LS, Fehrenbacher L, Moore MJ, Maroun JA, Ackland SP, Locker PK, Pirotta N, Elfring GL, Miller LL: Irinotecan plus fluorouracil and leucovorin for metastatic colorectal cancer. Irinotecan Study Group. New Engl J Med 2000, 343(13):905-914

13. Douillard JY, Cunningham D, Roth AD, Navarro M, James RD, Karasek $P$, Jandik P, Iveson T, Carmichael J, Alakl M, Gruia G, Awad L, Rougier P.
Irinotecan combined with fluorouracil compared with fluorouracil alone as first-line treatment for metastatic colorectal cancer: a multicentre randomised trial. Lancet 2000, 355(9209):1041-1047.

14. Andre T, Louvet C, Maindrault-Goebel F, Couteau C, Mabro M, Lotz JP, Gilles-Amar V, Krulik M, Carola E, Izrael V, de Gramont A: CPT-11 (irinotecan) addition to bimonthly, high-dose leucovorin and bolus and continuousinfusion 5-fluorouracil (FOLFIRI) for pretreated metastatic colorectal cancer. GERCOR. Eur J Cancer 1999, 35(9):1343-1347.

15. Garcia-Alfonso P, Munoz-Martin A, Mendez-Urena M, Quiben-Pereira R, Gonzalez-Flores E, Perez-Manga G: Capecitabine in combination with irinotecan (XELIRI), administered as a 2-weekly schedule, as first-line chemotherapy for patients with metastatic colorectal cancer: a phase II study of the Spanish GOTI group. Br J Cancer 2009, 101(7):1039-1043

16. Choi CK, Chan RT, Tung SY, Lui L, Siu S, Au GK, Ho JW, Law WL: Efficacy of combination chemotherapy with irinotecan (CPT-11) plus capecitabine in patients with metastatic or advanced colorectal carcinoma-a dual-centre phase II study: the MAC-6. Clin Oncol (R Coll Radiol) 2008, 20(2):168-175

17. Tournigand C, Andre T, Achille E, Lledo G, Flesh M, Mery-Mignard D, Quinaux E, Couteau C, Buyse M, Ganem G, Landi B, Colin P, Louvet C, de Gramont A: FOLFIRI followed by FOLFOX6 or the reverse sequence in advanced colorectal cancer: a randomized GERCOR study. J Clin Oncol 2004, 22(2):229-237.

18. DeVita VT, Lawrence TS, Rosenberg SA: DeVita, Hellman, and Rosenberg's cancer : principles \& practice of oncology. 9th edition. Philadelphia: Wolters Kluwer Health/Lippincott Williams \& Wilkins; 2011.

19. Hecht JR: Gastrointestinal toxicity or irinotecan. Oncology (Williston Park) 1998, 12(8 Suppl 6):72-78.

20. Pectasides D, Papaxoinis G, Kalogeras KT, Eleftheraki AG, Xanthakis I, Makatsoris T, Samantas E, Varthalitis I, Papakostas P, Nikitas N, Papandreou CN, Pentheroudakis G, Timotheadou E, Koutras A, Sgouros J, Bafaloukos D, Klouvas G, Economopoulos T, Syrigos KN, Fountzilas G: XELIRI-bevacizumab versus FOLFIRI-bevacizumab as first-line treatment in patients with metastatic colorectal cancer: a Hellenic Cooperative Oncology Group phase III trial with collateral biomarker analysis. BMC Cancer 2012, 12:271.

21. Van Cutsem E, Kohne CH, Hitre E, Zaluski J, Chang Chien CR, Makhson A, D'Haens G, Pinter T, Lim R, Bodoky G, Roh JK, Folprecht G, Ruff P, Stroh C, Tejpar S, Schlichting M, Nippgen J, Rougier P: Cetuximab and chemotherapy as initial treatment for metastatic colorectal cancer. New Engl J Med 2009, 360(14):1408-1417.

22. Hurwitz H, Fehrenbacher L, Novotny W, Cartwright T, Hainsworth J, Heim W, Berlin J, Baron A, Griffing S, Holmgren E, Ferrara N, Fyfe G, Rogers B, Ross R, Kabbinavar F: Bevacizumab plus irinotecan, fluorouracil, and leucovorin for metastatic colorectal cancer. New Engl J Med 2004, 350(23):2335-2342.

23. Douillard JY, Siena S, Cassidy J, Tabernero J, Burkes R, Barugel M, Humblet Y, Bodoky G, Cunningham D, Jassem J, Rivera F, Kocakova I, Ruff P, BlasinskaMorawiec M, Smakal M, Canon JL, Rother M, Oliner KS, Wolf M, Gansert J: Randomized, phase III trial of panitumumab with infusional fluorouracil, leucovorin, and oxaliplatin (FOLFOX4) versus FOLFOX4 alone as first-line treatment in patients with previously untreated metastatic colorectal cancer: the PRIME study. J Clin Oncol 2010, 28(31):4697-4705.

24. Rea DW, Nortier JW, Ten Bokkel Huinink WW, Falk S, Richel DJ, Maughan T, Groenewegen G, Smit JM, Steven N, Bakker JM, Semiond D, Kerr DJ, Punt $\mathrm{CJ}$ : A phase I/II and pharmacokinetic study of irinotecan in combination with capecitabine as first-line therapy for advanced colorectal cancer. Ann Oncol 2005, 16(7):1123-1132.

25. Goel S, Desai K, Karri S, Gollamudi R, Chaudhary I, Bulgaru A, Kaubisch A, Goldberg G, Einstein M, Camacho F, Baker S, Mani S: Pharmacokinetic and safety study of weekly irinotecan and oral capecitabine in patients with advanced solid cancers. Investig New Drugs 2007, 25(3):237-245.

26. Ducreux M, Adenis A, Pignon JP, Francois E, Chauffert B, Ichante JL, Boucher E, Ychou M, Pierga JY, Montoto-Grillot C, Conroy T: Efficacy and safety of bevacizumab-based combination regimens in patients with previously untreated metastatic colorectal cancer: Final results from a randomised phase ii study of bevacizumab plus 5 -fluorouracil, leucovorin plus irinotecan versus bevacizumab plus capecitabine plus irinotecan (FNCLCC ACCORD 13/0503 study). Eur J Cancer 2013, 49(6):1236-1245.

27. Souglakos J, Ziras N, Kakolyris S, Boukovinas I, Kentepozidis N, Makrantonakis P, Xynogalos S, Christophyllakis C, Kouroussis C, Vamvakas L, Georgoulias V, Polyzos A: Randomised phase-II trial of CAPIRI (capecitabine, irinotecan) 
plus bevacizumab vs FOLFIRI (folinic acid, 5 -fluorouracil, irinotecan) plus bevacizumab as first-line treatment of patients with unresectable/ metastatic colorectal cancer (mCRC). Br J Cancer 2012, 106(3):453-459.

28. Moosmann N, von Weikersthal LF, Vehling-Kaiser U, Stauch M, Hass HG, Dietzfelbinger H, Oruzio D, Klein S, Zellmann K, Decker T, Schulze M, Abenhardt W, Puchtler G, Kappauf H, Mittermuller J, Haberl C, Schalhorn A, Jung A, Stintzing $S$, Heinemann V: Cetuximab plus capecitabine and irinotecan compared with cetuximab plus capecitabine and oxaliplatin as first-line treatment for patients with metastatic colorectal cancer: AlO KRK-0104-a randomized trial of the German AIO CRC study group. J Clin Oncol 2011, 29(8):1050-1058.

29. Cartwright T, Kuefler P, Cohn A, Hyman W, Berger M, Richards D, Vukelja S, Nugent JE, Ruxer RL Jr, Boehm KA, Asmar L: Results of a phase II trial of cetuximab plus capecitabine/irinotecan as first-line therapy for patients with advanced and/or metastatic colorectal cancer. Clin Colorectal Cancer 2008, 7(6):390-397.

doi:10.1186/1471-2407-14-986

Cite this article as: Li et al:: Phase II study of weekly irinotecan and capecitabine treatment in metastatic colorectal cancer patients. BMC Cancer 2014 14:986.

\section{Submit your next manuscript to BioMed Central and take full advantage of:}

- Convenient online submission

- Thorough peer review

- No space constraints or color figure charges

- Immediate publication on acceptance

- Inclusion in PubMed, CAS, Scopus and Google Scholar

- Research which is freely available for redistribution 